\title{
FLAVONOID COMPOUNDS IDENTIFIED IN ALCHEMILLA L. SPECIES COLLECTED IN THE NORTH-EASTERN BLACK SEA REGION OF TURKEY
}

\author{
Bülent Kaya $^{{ }^{*}}$, Yusuf Menemen ${ }^{2}$, Fatma Zerrin Saltan ${ }^{3}$ \\ ${ }^{1 *}$ Department of Biology, Faculty of Science and Art, Bingöl University, 12000 Bingöl, TURKEY, \\ ${ }^{2}$ Department of Biology, Faculty of Science and Art, Kırıkkale University, 71450 Kırıkkale, TURKEY, \\ ${ }^{3}$ Plant, Drug and Scientific Research Center (AUBIBAM), Anadolu University, Yunusemre Campus,26470, Eskişehir, \\ TURKEY, \\ Email: b_kaya_tr@yahoo.com
}

\begin{abstract}
This study identified flavonoid glycosides in species of the genus Alchemilla, A. procerrima, A. stricta, A. hirtipedicellata and A. sericata. A. procerrima is an endemic species for Turkey. After detailed investigation, flavonoid compounds of the species were identified for the first time. In this study, flavonoid compounds were determined by using two different chromatography techniques, TLC and HPLC. The following flavonoid compounds were identified from the Alchemilla species studied. They are as follows: orientin (luteolin-8-C-glucoside) $R f: 0,70$, vitexin (apigenin- 8 - $C$-glucoside) $R f: 0,77$ as flavone- $C$-glycoside, rutin (quercetin-3-O-rutinoside) $R f: 0,44$, hyperoside (quercetin-3-O-galactoside) $R f: 0,65$, isoquercetin (quercetin-3-O-glucopyranoside) $R f: 0,72$, quercitrin (quercetin-3-O-rhamnoside) $R f: 0,84$ as flavonol- $O$ glycoside. Three more folavonoids with $R f$ values of $R f_{1}=0,36, R f_{2}=0,54$ and $R f_{3}=0,68$ were also identified for the first time in this study. Rutin (quercetin-3-O-rutinoside) and the flavonoid glycoside, shown as $R f_{2}$ were found in all species. Quercitrin and isoquercetin were determined in all analysed species but $A$. procerrima. Hyperoside was identified in all species except for $A$. stricta. Vitexin was determined only in A.stricta. Orientin was determined in A. procerrima and A. stricta, but could not be determined in $A$. sericata and $A$. hirtpedicellata. Unknown flavonoid with $R f_{1}$ and $R f_{3}$ were determined outside of $A$. sericata. Description of these compounds in Turkish Alchemilla plants for the first time should be viewed as a discovery of an important chemosystematic feature.
\end{abstract}

Keywords: Alchemilla L., Rosaceae, Flavonol-O-glycoside, Flavone-C-glycoside, TLC, HPLC.

\section{Introduction}

The genus Alchemilla L. belongs to the Rosaceae family. This large family includes herbaceous and woody plants. Zomlefer (1994) recognised the family as a monophyletic group. Based upon the gynoecial and fruit characters, the family is typically divided into four subfamilies. Approximately 115 genera and 3,500 species of this family have a much larger spread along the Northern Hemisphere. Berry-like fruits of the family members used as food are particularly important. Furthermore, these plants are used as ornamental plants in parks and gardens (Seçmen et al., 2000).

Alchemilla was first described by Linnaeus (1753). The genus is included in the tribus Sanguisorbaeae of Rosoideae subfamily. Alchemilla species are represented by more than 1,000 species, often spread along the Holarctic region. They can also be found in Ceylon, East Indies, the Cape Mountains and East Africa (Hayırlığlu-Ayaz and İnceer 2009; Izmailow 1981; Fröhner 1995). Alchemilla is divided into seven sections; European material in two sections, section Brevicaules and section Brevicaules by Rothmaler (Gehrke et al. 2008). According to the records of the Flora of Turkey, all Alchemilla species distributed in Turkey belong to the section Alchemilla (Pawlowski and Walters, 1972). They are further subdivided into three subsections (Chirophyllum Rothm., Heliodrosium Rothm. and Calycanthum Rothm.) and 6 series (Saxatiles Bus., Sericeae Bus., Pubescentes Bus., Vulgares Bus., Elatae Rothm. and Calycinae Bus.) The majority of Turkish Alchemilla species are distributed along the northern Anatolia (Pawlowski and Walters, 1972). Except for a few species, embryological studies have shown that, the genus Alchemilla has apomictic features (Strasburger, 1905; Murbeck, 1901).

Flavonoids are plant-based compounds and are commonly found in nature. The very first was derived from a lemon peel and called vitamin P (Rusznyak and Györgyi, 1936). Its use to reduce capillary permeability and fragility has increased the importance of flavonoids. As of today, more than 4,000 flavonoids have been isolated and analyzed for their structure using different chemical methods (Bilaloğlu and Harmandar, 1999).

Flavonoids are among the most important groups of natural products, and are widespread in nature. Some group members, such as those found to be the plant constituents that contribute to the formation of its colour, are very influential when it comes to physiological activity (Harborne et al., 1975). Studies of these compounds have found that they are not only concerned with discoloration, they also protect against UV lights and plant pathogens (bacteria and fungi), as well as agents capable of impairing biochemical functions, such as antioxidants and enzyme inhibitors (Harborne et al., 1975; Harborne and Mabry, 1982), In their study of roles played by flavonoids present in plants, Smith and Banks (1986) demonstrated their impact on energy conversion and growth hormone by acting on regulation, respiration and photosynthesis, and their ability to defend a plant against infectious diseases. Moreover, Bilaloğlu and Harmandar (1999) reported that Şamray's studies (1970) have shown that flavonoids reduce cholesterol levels in blood components, and various researchers have conducted several studies on various flavonoids, and have demonstrated their antioxidative, anti-inflammatory, antimicrobial, anti-ulcer, antiviral, hypolipidemic and hepatoprotective effects (Bors and Saran, 1987; Larson, 1988; Moroney et al., 1988; Verma et 
al., 1988; Wagner, 1989; Pratt and Hudson 1990; Wagner et al., 1991; Hikino and Kiso, 1988). Flavonoids have been extensively used as taxonomic features in plant taxonomy. The study by Harborne (1973) provided important evidence that flavonoids pose as identifiers of native plant hybrids of the genus Baptisia. Following this path, in their work with cultivated plants such as Humulus lupulus, and Azalea on both species and genus levels, Van Sumere et al. (1993) showed that certain flavonoid compounds may be used with success. This study was done to identify flavonoids in Alchemilla species of Turkey.

\section{Materials and methods Standards and solvents}

In this study, quercetin, rutin, isorhamnetin, kaempferol, apigenin, and luteolin were used as standards; they were obtained from Sigma-Aldrich (St. Louis, MO, USA). The remaining standards hyperoside, quercitrin, isoquercitrin, vitexin, orientin, myricetin, naringenin, hesperidin were obtained from Extrasyntese (Genay / France). All solvents including those of HPLC were of analytical grade and were obtained from Riedel-de Haen Company (Seelze, Germany). Thin layer chromatography silica gel 60 F254 aluminium plates, measuring $20 \times 20 \mathrm{~cm}$ in size and having a $0.1 \mathrm{~mm}$ thickness were obtained from Merck (Darmstadt / Germany).

\section{Plant material}

Alchemilla L. species were collected in July 2008 in Trabzon on the highway which connects it with Gümüşhane. Their botanical identity was confirmed by one of the authors (Y.M.).

\section{Extraction of flavonoid compounds}

Extraction method used in this study was a modification of the method exercised by Mingbo et al. (2005). Dried and powdered plant material $(10 \mathrm{gr})$ was successively extracted in a flask using $50 \%$ aqueous ethanol. The extract was subjected to maceration process taking place in an incubator for four hours at $150 \mathrm{rpm}, 50{ }^{\circ} \mathrm{C}$. The plant material was left to macerate for 20 hours. Following this procedure, the extract was filtered using a blue band filter paper and Buchner funnel. The hydroalcohol solution was evaporated to dryness under a reduced pressure. Hydrolic extract was treated with petroleum ether $\left(40^{\circ}-60^{\circ}\right)$ in a separation funnel and transferred in the aqueous phase to another separation funnel. After ethyl acetate was added, the funnel was gently mixed. It was found that ethyl acetate was a part of the separation funnel. The ethyl acetate was evaporated to dryness under a reduced pressure. The soluble material $(0.7-0.8 \mathrm{~g})$ was subjected to thin layer chromatography and HPLC. This extract was used for chromatographic analysis. Three thousand (3000) micrograms of this extract were dissolved in $1 \mathrm{ml}$ methanol. Some of these samples were diluted and made available for TLC and HPLC chromatographic analysis.

\section{Analysis of flavonoid glycosides using TLC}

The following standard solutions were prepared. Each flavonoid $(5 \mathrm{mg})$ was dissolved in $10 \mathrm{ml}$ methanol. TLC was performed using silica plate according to Wagner and Bladt (1996). These plates were actually aluminium sheets coated with silica gel $\mathrm{GF}_{254}($ Merck 20x20 cm). Flavonoids were analyzed on TLC plates. Concentrated ethyl acetate solution was directly filled with standard flavonoid solutions $1 \mathrm{~cm}$ from the bottom (as spots) using a capillary tube on the silica plates and using ethyl acetate: acetic acid: formic acid: water (100:11:11:27 v/v) as a running (mobile phase) solvent. Suitable mobile phase was loaded into a tank. After that, at least half an hour of solvent vapourisation inside the running tank was expected to achieve balance. Then a plate was developed in a balanced running tank. The running process was allowed to leave the mobile phase to reach the top point of up to $1.5 \mathrm{~cm}$. The developed plates were removed from the tank and then dried in a fume cupboard. Coloured and colourless bands emerged on the plate under the UV light at $\lambda=254 \mathrm{~nm}$. Then all spots on the dried plate were treated with NP and PEG (Natural Product Reagent (1\% methanol diphenylboryloxyethylamine) / Poly Ethylen Glycol 4000 (5\% ethanol polyethylene glycol 4000)) and colourless spots emerged under the UV light at $\lambda=365 \mathrm{~nm}$. On chromatograms, flavonoids appeared as orange-yellow bands or spots. Flavonoids were determined by virtue of comparison with $R f$ values and colour characteristics of the standards. $\mathrm{R}_{\mathrm{f}}$ values of the standards are given in Table 1 . The chromatograms are shown in Figure 1. Chromatogram of each plant species can be seen on two specific photographs. The actual photo has a navy blue background. The other is a reversal of the colours obtained after manipulation.

\section{Analysis of flavonoid glycosides using HPLC}

Qualitative analysis of flavonoid glycosides was completed using a high performance liquid chromatography with direct injection auto-sampler. Qualification was carried out using HPLC Dionex (U.S.A). The system consists of a ASI-10 auto-sampler, a P580 pump, STH 585 column heater and UVD 170S UV visible detector. Data were collected and analyzed using Chromelon chromatography software (Fang et al., 2007). Separation and identification was carried out using C18 silica column. This column was 250 x $4.6 \mathrm{~mm}$ i.d. $5 \mu \mathrm{m}$ particle size (Dionex Corp., USA). Column was placed in the oven set at 27 degrees Celsius. The flow rate was adjusted to $1 \mathrm{ml} / \mathrm{min}$ isocratic elution. Mobile phase made use of acetic acid-methanolwater (5:36:59). Before loading, sample mobile phase was put onto the column. The injection volume was adjusted to $10 \mu 1$. The 
A

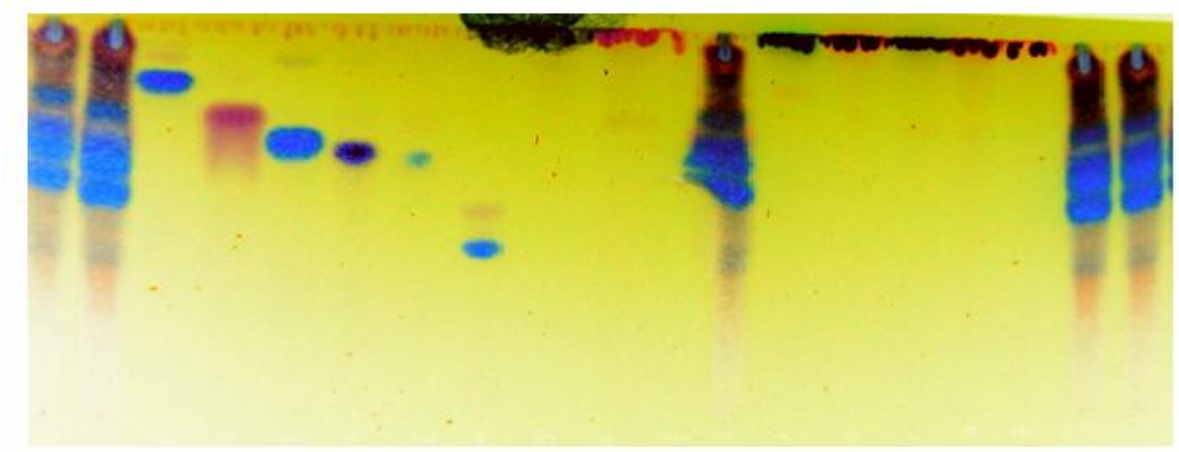

\begin{tabular}{|l|l|l|l|l|l|l|l|l|l|l|l|l|l|l|l|}
\hline Sample & Qci & Vit & Iso & Ori & Hy & Rut & My & Na & Sample & Qe & Ka & Lu & Api & Isor & Sample \\
\hline
\end{tabular}

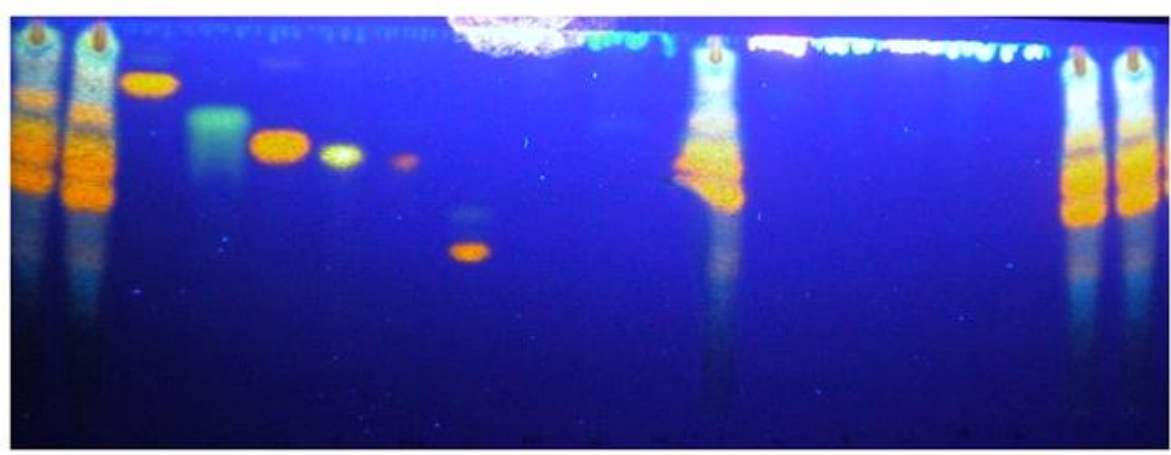

\begin{tabular}{|l|l|l|l|l|l|l|l|l|l|ll|l|l|l|l|}
\hline Sample & Qci & Vit & Eo & Ori & Hy & Rut & My. & Ha & Sample & Qe & Ka & Lu & Ápi. & Isor & Sample \\
\hline
\end{tabular}
C

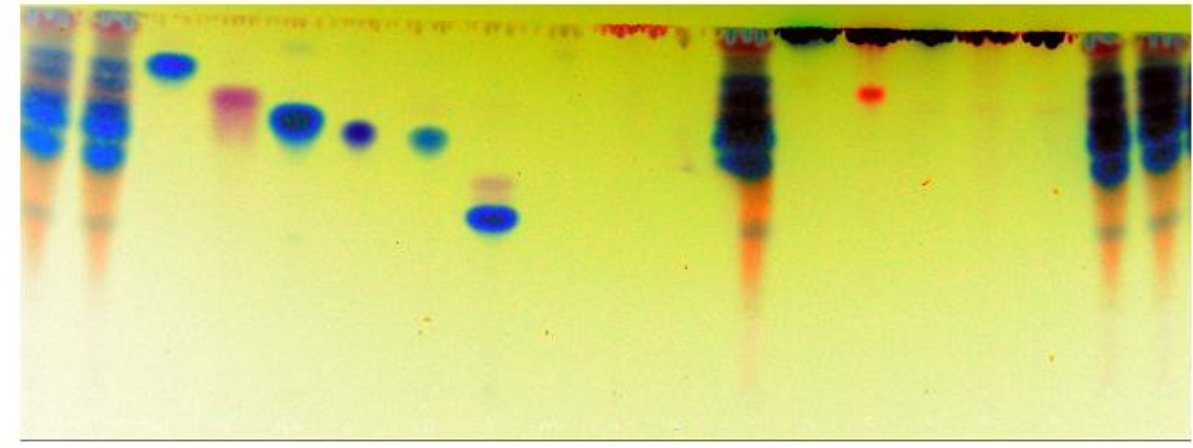

\begin{tabular}{|l|l|l|l|l|l|l|l|l|l|l|l|l|l|l|l|}
\hline Sample & Qci & Vit & Iso & Ori & Hy & Rut & My. & Ha & Sample & Qe & Ka & Lu & Api. & Eor & Sample \\
\hline
\end{tabular}

D

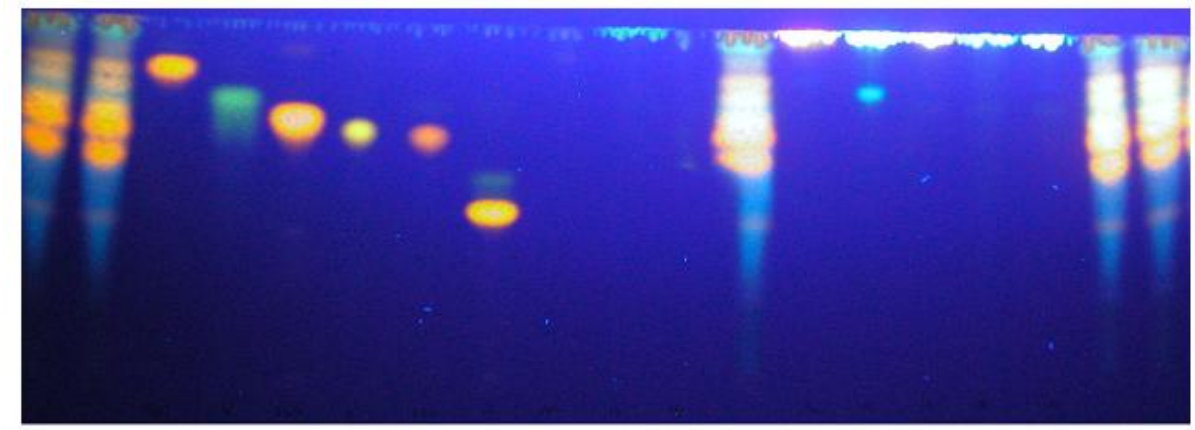

\begin{tabular}{|l|l|l|l|l|ll|l|ll|l|l|lll|l|}
\hline Sample & Qci & Vit & Iso & Ori & Hy & Kunt & My. & Na & Sample & Qe & Ka & Lu & Api. & Isor & Sample \\
\hline
\end{tabular} 
Publisher: African Networks on Ethnomedicines

Web page: /http://journals.sfu.ca/africanem/index.php/ajtcam/index

$\frac{\mathrm{http}: / / \mathrm{dx} . \text { doi.org/10.4314/ajtcam.v9i3.18 }}{\mathrm{F}}$

H
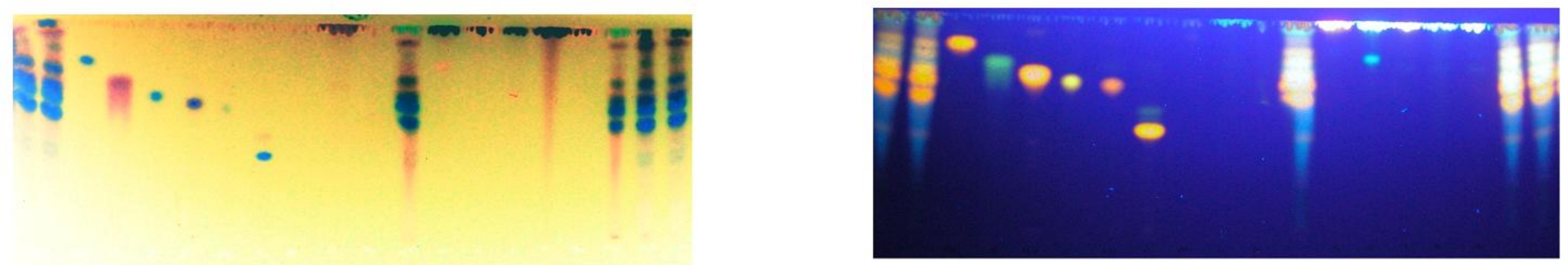

G

$\mathrm{F}$
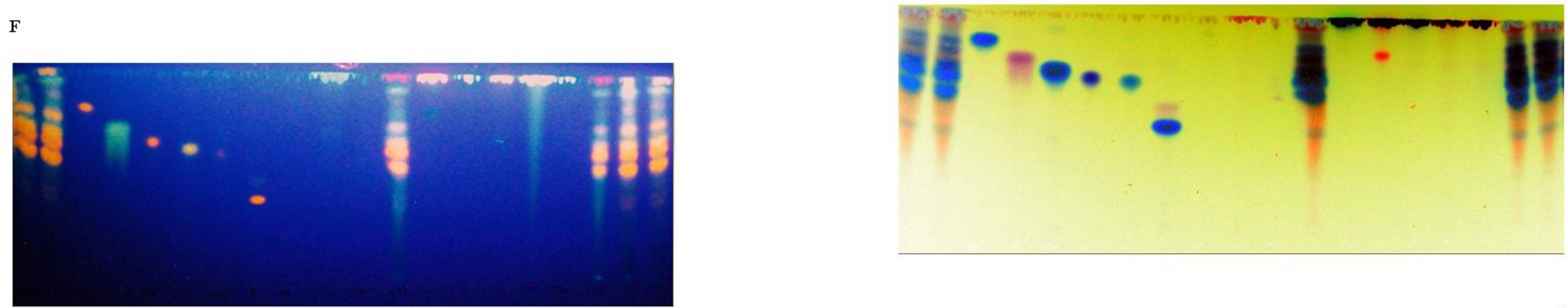

\begin{tabular}{|l|l|l|l|l|ll|l|l|l|l|l|l|l|l|l|}
\hline Sample & Qci & Vit & iso & Ori & Hy. & Rut & My & Na & Sample & Qe & Kam & Lut & Api. & Isor. & Sample \\
\hline
\end{tabular}

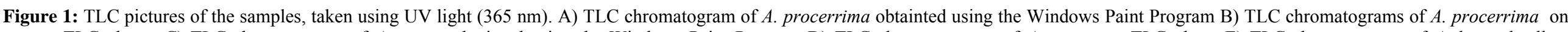
TLC plates C) TLC chromatogram of A. stricta obtainted using the Windows Paint Program D) TLC chromatograms of $A$. stricta on TLC plates E) TLC chromatogram of $A$. hirtpedicellata obtainted using the Windows Paint Program F) TLC Chromatograms of $A$. hirtpedicellata on TLC plates G) TLC chromatogram of $A$. sericata obtainted using the Windows Paint Program H) TLC Chromatograms of A. sericata on TLC plates; the following abbreviations were used: Qci: Quercitrin, Vit: Vitexin, İso: İsoquercetin, Ori: Orientin Hy: Hyperoside, Rut: Rutin, My: Myricetin, Na: Naringenin, Qe: Quercetin, Ka: Kaempferol Lu: Lutein, Api: Apigenin, Isor: Isorhamnetin, Sample: Alchemilla species. 
Publisher: African Networks on Ethnomedicines

Web page: /http://journals.sfu.ca/africanem/index.php/ajtcam/index

http://dx.doi.org/10.4314/ajtcam.v9i3.18
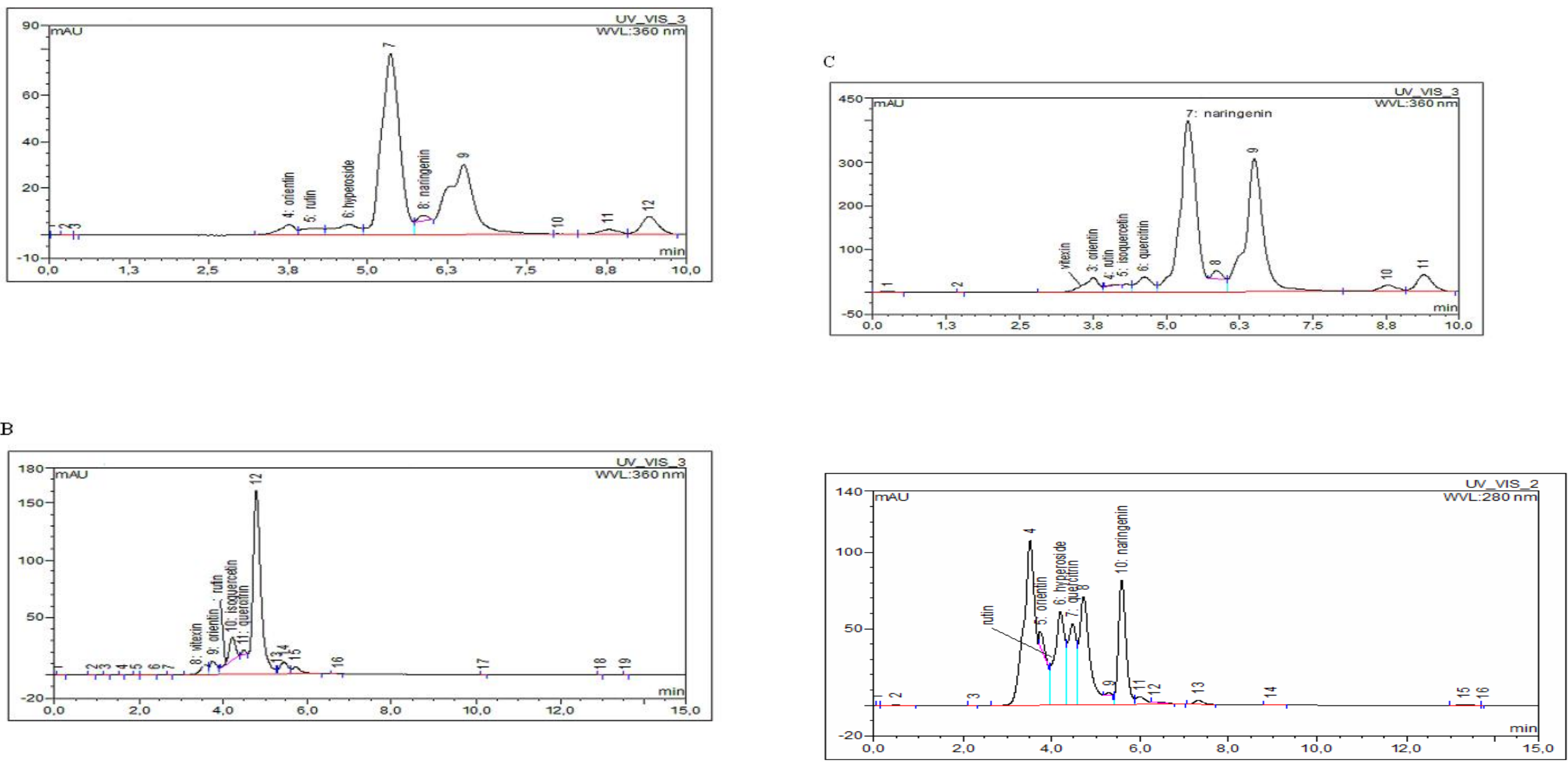

Figure 2: HPLC chromatograms of samples A) A. procerrima B) A. stricta C) A. hirtpedicellata

D) A. sericata

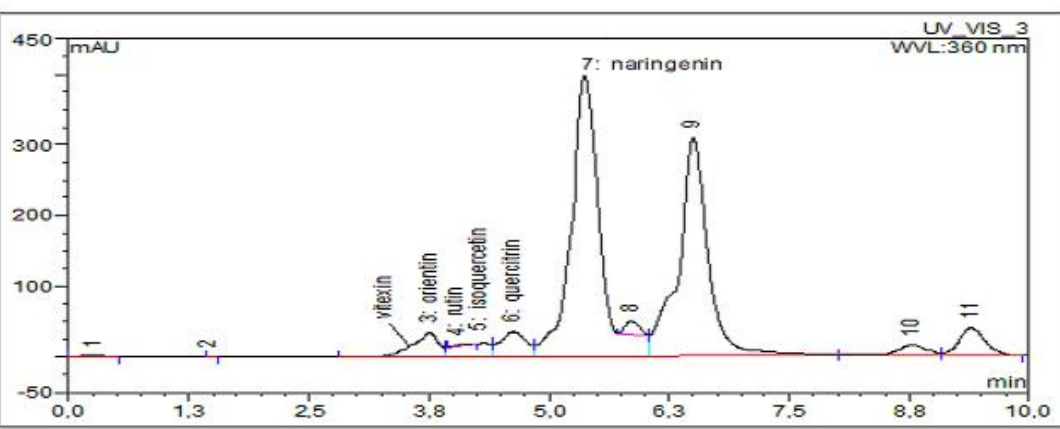


monitoring peaks were detected at 254, 280 and $360 \mathrm{~nm}$ using the automated Chromelon chromatography software. The Alchemilla samples, standard solutions and mobile phases were filtered using a $0.45-\mu \mathrm{m}$ pore size membrane filter. The filtered standard and ethyl acetate extract were injected under these conditions. The identity of HPLC peaks was confirmed using the injection of authentic standards. The purity of each peak identified in Figure 2 was determined by virtue of comparison of the UV spectra at the upslope and down-slope inflexion points.

Table 1: $R f$ values of flavonoid compounds identified and their colours on TLC chromatogram under the UV light

\begin{tabular}{lcc}
\hline Flavonoids & Rf values & Colour under UV $365 \mathrm{~nm}$ \\
\hline Rutin & 0.44 & Orange \\
Hyperoside & 0.65 & Orange \\
Orientin & 0.70 & Yellow \\
Isoquercetin & 0.72 & Orange \\
Vitexin & 0.77 & Green
\end{tabular}

Table 2 Flavonoid compounds of Alchemilla species identified on TLC chromatogram

\begin{tabular}{|c|c|c|c|c|c|c|c|c|c|}
\hline A. procerrima & + & -- & + & + & -- & -- & + & + & + \\
\hline A. stricta & + & + & + & -- & + & + & + & + & + \\
\hline A. hirtpedicellata & -- & -- & + & + & + & + & + & + & + \\
\hline A. sericata & -- & -- & + & + & + & + & -- & + & -- \\
\hline
\end{tabular}

\section{Results and Discussion}

Flavonoid glycosides of Alchemilla L. species were determined. Flavonoid glycosides and their type present in Alchemilla species were identified using chromatographic techniques. Selected chromatographic techniques were used in combination with each other. The obtained TLC and HPLC data were mutually supportive. TLC was started first and made use of standard silica layers. On these layers, ethanolic extracts were applied together with standard flavonoid glycosides. Standards and extracts applied on TLC plates were compared for their $R f$ values. Extracts and standard flavonoids compounds were determined by TLC analysis. As a result of the comparison of Rf values, and colour changes with NP / PEG under UV light, the flavonoid compounds in Alchemilla species were identified. Flavonoid compounds found in the species studies are rutin (quercetin-3-O-rutinoside), hyperoside (quercetin-3-O-galactoside), isoquercetin (quercetin-3-Oglucopyranoside), quercitrin (quercetin-3-O-rhamnoside), orientin (luteolin-8-C-glucoside), vitexin (apigenin-8- $C$-glucoside), and unknown flavonoids with $R f_{l}=0.36, R f_{2}=0.54$ and $R f_{3}=0.68$. This is the first time these flavonoid glycosides are been 
reported in Alchemilla species studied. Detailed distribution of the flavonoid compounds in the species are given in Table 2. HPLC studies were done in the above-described manner using liquid chromatography.

Flavonoid glycosides obtained in this study were analyzed and compared with literature data. They were generally proven to be the same as those obtained from the Rosaceae family. Most of the Turkish Alchemilla species are distributed in Northeast Anatolia (Turkey) and the genus includes many endemic species. Studies devoted to flavonoids of the genus Alchemilla have been found to be very few in numbers. Fraisse et al. (2000) found quercetin 3-O-arabinopyranoside to be the main flavonoid compound of A. xanthochlora. Olafsdottir et al. (2001) studied three Alchemilla species (A. faeroensis, A. alpina and A.vulgaris) from Iceland. They did not find any flavonoid compounds in the studied plant materials. In another study, quercetin-3- $O-\beta$ - $D$-glucopyranoside, quercetin-3- $O-\beta$ - $D$-rutinoside, quercetin-3- $O-\alpha-D$-arabinofuranoside, and 3-Okaempferol-6"'-O-(p-coumaroyl)- $\beta$ - $D$-glucopyranoside were identified in Alchemilla vulgaris by D'Agostino et al. (1998). According to Challice (1981), flavonol $O$-glycosides are common for the Rosaceae family. In their 2003 study with Cotoneaster wilsonii (Rosaceae) belonging to the Rosaceae family, Chang and Jeon listed the following flavonoids as present: (flavonol $O$-glycosides) quercetin 3-O-glucoside, quercetin 3-O-rhamnoside, quercetin-3-O-rhamnoglucoside, isorhamnetin-3-O-galactoside, isorhamnetin-3-O-rhamnose-glucose (Me- $O$-glycosides), vicenin $\mathrm{A}$, vicenin $\mathrm{B}$, luteolin 6-Cglycoside (Flavone- $C$-glycosylflavone), apigenin-7- $O$-glucoside, luteolin-7- $O$-glucoside (Flavone- $O$-glycoside). In 2003, Zhang and $\mathrm{Xu}$ did the study with Crataegus pinnatifida and found two new flavonoid acetyl- $C$-glucosides. These flavonoids were purified with the previously known four flavonoid- $C$-glycosides. In their studies, Mikanagi et al. (1995) identified 19 flavonols, and six anthocyanins in the 120 taxa of sub-genus Rosa, as follows: six kaempferol (K) glycosides, 3-glucoside (99\% taxa), 3-rutinoside (63\%), 3-sophoroside (60\%), 3-rhamnoside (70\%), 7-glucoside (94\%) and 4 "-glucoside (4\%), and six quercetin ((3) glycosides: 3-glucoside (91\%), 3-glucuronide (62\%), 3-rutinoside (63\%), 3-sophoroside (69\%), 7-glucoside $(90 \%)$ ) and 4'-glucoside (4\%), and seven unidentified flavonols, and two cyanidin glycosides, 3,5-diglucoside (68\%) and 3glucoside (16\%) and two peonidin glycosides; 3,5-diglucoside (41\%) and 3-glucoside (4\%) and two unidentified anthocyanins. From the flavonoid distribution patterns of this analysis, 120 taxa in the subgenus Rosa were divided into three groups.

Studies aiming to determine flavonoid contents of the genus Alchemilla are only few in number. According to the literature, flavonoid contents of Alchemilla species are generally quercetin derivatives. The results of this study are similar to the information given in the literature for Rosaceae family and Alchemilla species. In this study, four flavonol glycosides and two flavone glycosides were found for the first time in four Alchemilla species, A. procerrima, A. stricta, A. hirtpedicellata and $A$. sericata. The flavonoids determined in this study are flavonol $O$-glycosides and flavone $C$-glycosides. This is the first determination of flavone $C$-glycosides, orientin (luteolin-8- $C$-glucoside) and vitexin (apigenin- 8 - $C$-glucoside), and flavonol $O$-glycosides, hyperoside (quercetin-3-O-galactoside) and quercitrin (quercetin-3-O-rhamnoside) in Alchemilla. In addition to other flavonoids, rutin (quercetin-3-O-rutinoside) was determined in all and isoquercitrin (quercetin-3-O-glucopyranoside) in three Alchemilla species studied for the first time ever.

\section{References}

1. Bilaloğlu, G. V., Harmandar, M. (1999). Flavonoidler, Aktif Yayınevi, İstanbul.

2. Bors, W., Saran M. (1987). Radical scavenging by flavonoid antioxidants. Free Radic. Res. Commun., 2: 289-294.

3. Challice, J. (1981). The genus Micromeles revisited, Folia Geobot. Phytotx., 16: 181-193.

4. Chang, C-S., Jeon, J.I. (2003). Leaf flavonoids in Cotoneaster wilsonii (Rosaceae) from the island Ulleung-do, Korea. Biochem. Syst. Ecol., 31: 171-179.

5. D’Agostino, M., Dini, I., Ramundo, E., Senatore, F. (1998). Flavonoid Glycosides of Alchemilla vulgaris L., Phytother. Res., 12: 162-163.

6. $\quad$ Fang Z., Zhang M., Wang L., 2007, HPLC-DAD-ESIMS analysis of phenolic compounds in bayberries (Myrica rubra Sieb. et Zucc.), Food Chemistry, 100: 845-852.

7. Fraisse, D., Heitz, A., Carnat, A., Carnat, A. P., Lamaison, J. L. (2000). Quercetin 3-arabinopyranoside, a major flavonoid compound from Alchemilla xanthochlora, Fitoterapia., 71: 463-464.

8. Fröhner, S. (1995). Alchemilla L. In: Illustrierte Flora von Mitteleuropa. (Ed.): G.Hegi, Blackwell, WissenschaftsVerlag: Berlin-Vien.

9. Gehrke, B., Bräuchler, C., Romoleroux, K., Lundberg, M., Heubl, G. \& Eriksson, T. (2008). Molecular phylogenetics of Alchemilla, Aphanes and Lachemilla (Rosaceae) inferred from plastid and nuclear intron and spacer DNA sequences, with comments on generic classification. Mol. Phyl. Evol. 47: 1030-1044.

10. Harborne, J. B. (1973). Chemistry in Botanical Classification. Proceedings of the Twenty-Fifth Nobel Symposium, Academic Press, Sweden, New York and London.

11. Harborne, J. B., Mabry, T. J. (1982). The Flavonoids, Chapman and Hall, London.

12. Harborne, J. B., Mabry, T. J., Mabry, H. (1975). Flavonoids, Chapman and Hall, London.

13. Hikino, H., Kiso, Y. (1988). Economic and Medicinal Plant Research, Academic Press, London.

14. Hayırlığlu-Ayaz S., İnceer, H. 2009. Three new Alchemilla L. (Rosaceae) records from Turkey. Pak. J. Bot. 41(5): 2093-2096.

15. Izmailow, R. (1981). Karyological studies in species of Alchemilla L. from the series Calycinae Bus. (Section Brevicaulon Rothm.).Acta. Biol. Cracov. Ser. Bot., 23: 117-130.

16. Larson, R. A. (1988). The antioxidants of higher plants. Phytochem., 27: 969 -978.

17. Linnaeus, C. (1753). Alchemilla L., Sp. Pl., 1: 123.

18. Mikanagi, Y., Yokoi, M., Ueda, Y., Saito, N. (1995). Flower Flavonol and Anthocyanin Distribution in Subgenus Rosa, Biochem. Syst. Ecol., 23: 183-200. 
Publisher: African Networks on Ethnomedicines

Web page: /http://journals.sfu.ca/africanem/index.php/ajtcam/index

http://dx.doi.org/10.4314/ajtcam.v9i3.18

19. Mingbo, Z., Yoichiro, I., Pengfei, T. (2005). Isolation of a novel flavanone 6-glucoside from the flowers of Carthamus tinctorium (Honghua) by high-speed counter-current chromatography, J. Chromatogr. A., 1090: 193-196.

20. Moroney, M. A., Alcanaz, M. J., Forder, R. A., Carey, F., Hoult, J. R. F. (1988). Selectivity of neutrophil 5lipoxygenase and cyclooxygenase inhibition by an anti-inflammatory flavonoid glycoside and related aglycone flavonoids Pharm. Pharmacol., 40: 787-792.

21. Murbeck, S. (1901). Parthenogenetische Embryobildung in der Gattung Alchemilla, Lunds Univ. Årsskr., $36: 1-41$.

22. Olafsdottir, E. S., Omarsdottir, S., Jaroszewski, J. W. (2001). Constituents of three Icelandic Alchemilla species. Biochem. Syst. Ecol., 29: 959-962.

23. Pawlowski, B., Walters, S. M. (1972) Alchemilla L. — In: Davis, P. H. (ed.), Flora of Turkey and the East Aegean Islands 4: 80-105. Edinburgh Univ. Press, Edinburgh.

24. Pratt, D. E., Hudson, B. J. F. (1990).Food Antioxidants, Elsevier, London.

25. Rusznyak, S., Györgyi S.A. (1936). Vitamin P: Flavonols as vitamin. Nature., 138: 27.

26. Şamray, E. F. (1970). Ukr. Biox. J.,42: 265.

27. Seçmen, Ö., Gemici, Y., Görk, G., Bekat, L., Leblebici, E. (2000). Tohumlu Bitkiler Sistematiği, Ege Üniversitesi Basımevi, Bornova-İzmir.

28. Smith, D. A., Banks, S. W. (1986). Plant flavonoids in biology and medicine: Biochemical, pharmacological and structure-activity relationships, in: Cody, V., Middleton, E., Jr., and Harborne, J. B. (Eds.) Alan R. Liss INC., New York. pp.113-124.

29. Strasburger, E. (1905). Die apogamie der Eualchemillen und allgemeine Gesichtspunkte, die sich aus ihr erge- ben. Jahrb. F. Wiss. Bot., 41:88-164.

30. Van Sumere, C. F., De Cooman L., Everaert, E., De Keukeleire, D., Vande Casteele, K. (1993). Polyphenolic Phenomena, INRA, Paris.

31. Verma, A. K., Johnson, J. A., Goluld, M. N., Tanner, M. (1988). Inhibition of 7, 12-Dimethylbenz (a)anthraceneand $N$-Nitrosomethylurea-induced Rat Mammary Cancer by Dietary Flavonol Quercetin, Cancer Res. 48: 5754- 5758

32. Wagner, H. (1989). Pluntu Med. 55: 235

33. Wagner, H., Bladt, S. (1996). Plant Drug Analysis, Springer-Verlag, Berlin.

34. Wagner, H., Elbl, G., Lotter, H., Guinea, M. (1991). Evaluation of natural products as inhibitors of agiotensin Iconverting enzyme (ACE), Pharm. Pharmacol. 1:15

35. Zhang, P-C. Xu, S-X. (2003). Two New C-glucoside Flavonoids from the Leaves of Crataegus pinnatifida Bge. Var. major N.E.Br', J. Asi. Nat. Prod. Res. 5: 131-136

36. Zomlefer, W. B. (1994). Guide to Flowering Plant Families, University of North Carolina press, North Carolina. 